\title{
Anthrovision
}

Vaneasa Online Journal

\section{Collaborative and Interactive Presentation: Tracks of A Discipline Evolution}

Présentation interactive et collaborative: sur les traces de l'évolution d'une discipline

Presentación interactiva y colaborativa : siguendo las huellas de la evolución de una disciplina

\section{Gilles Remillet and Nadine Wanono}

\section{(2) OpenEdition Journals}

Electronic version

URL: http://journals.openedition.org/anthrovision/1417

DOI: 10.4000/anthrovision. 1417

ISSN: 2198-6754

\section{Publisher}

VANEASA - Visual Anthropology Network of European Association of Social Anthropologists

Electronic reference

Gilles Remillet and Nadine Wanono, «Collaborative and Interactive Presentation: Tracks Of A

Discipline Evolution », Anthrovision [Online], 2.2 | 2014, Online since 02 January 2015, connection on 03 May 2019. URL : http://journals.openedition.org/anthrovision/1417 ; DOI : 10.4000/anthrovision. 1417

This text was automatically generated on 3 May 2019.

(c) Anthrovision 


\section{Collaborative and Interactive Presentation: Tracks of A Discipline Evolution}

Présentation interactive et collaborative: sur les traces de l'évolution d'une

discipline

Presentación interactiva y colaborativa : siguendo las huellas de la evolución de una disciplina

\section{Gilles Remillet and Nadine Wanono}

Presentación interactiva y colaborativa: siguendo lashuellas de la evolución de una disciplin

1 Since its institutional recognition in 1973 (Hockings, 1975) Visual Anthropology has always been a two-headed discipline rooted both in art and science. From the theoretical proposals, which emerged from the introduction of direct cinema (1960) in ethnography (Heusch, 1962, Marcorelles, 1970) soon after 1980 many anthropologists became filmmakers and explored the creative power and heuristic capacities in/of documentary film.

2 However, even within the research framework offered by a reflexive epistemology (Jay Ruby, 1993) or a dialogic one (M.H. Piault, 2000) we have to admit the limitation of this kind of scientific representation, which didn't fully render the complexities and richness of some of the anthropological situations represented.

3 Currently, numerous projects that are being developed within the digital technologies or within a collaborative framework reintroduce well-known concepts such as that of "shared knowledge", and make forms of hybrid production possible. These researches and productions offered us an account of the multiplicity of practices, representations and narratives that are proposing an open space where filmmakers and subjects' interrogations could be fully integrated in the project process. On the one hand these productions force us to carefully reconsider the notion of fieldwork; on the other hand 
new forms of production of anthropological knowledge are introduced in the discipline. The notions of authorship, scenario, protagonist, narrativity, as they are becoming fully integrated in the field of digital writing or digital conception within visual anthropology, underline the shift that occurs in this discipline.

Even if digital technologies or open access software are easily accessible for the researchers, anthropologists-filmmakers are facing real difficulties to publish film and text jointly and to have a scientific recognition of the publication itself. Online journals are offering more opportunities to the discipline by giving an academic space where the authors can propose new forms of articles, but we couldn't forget how strongly articulated we should be in order to gain acknowledgement, as already 13 years ago Xoana $^{1}$ dedicated a special issue on anthropology and multimedia. In 2013, the visual anthropologist community is still fighting to gain an academic recognition of the rich and complex body of work offered by film and writing.

5 Deeply concerned with this challenge and with offering new forms of interactive, multimodal and multilayer productions of data, we decided to develop a research project. The four of us $^{2}$ chose to put in place an audio-visual and textual collaboration project to be presented during the $17^{\text {th }}$ IUAES World Congress in Manchester, addressing the issue of establishing academic standards of evaluation for non-literary forms of representation in Anthropology. As French scholars, we were motivated to share our research abroad, our interrogations and also our abilities in order to fill the gap between English speaking networks and French scholars.

Our idea was to document the process of our cooperation in detail, following the different phases of its conception and the final presentation choices, in order to lay out our research action and its result: this was a webpage, produced with a Parallax structure including text and film. Collaborating together for the first time, we realized how important it was to work in an associative space outside any academic institution in order to freely convey our research, and also to precisely identify our genealogical academic roots and their resonances in our cooperation. By describing and analysing the modalities of this experimental production, we will underline the key moments revealing the challenges, the interest and the questions we would like to share in order to encourage this experimental approach and this dynamic of creation as part of a possible methodology.

\section{Text and Pictures: long-term cooperation}

7 The heterogeneous nature of the elements integrated in this production (field notes, rushes, filmic edited material, photo, interpretation, and synthesis) echoed the work of Warburg, when he established links and signification between visual elements without continuity of space and time. Please take a look at the multimedia project in its current online at http://phanieethnoimage.free.fr/.

8 All the visual elements from our collaborative work have been cautiously selected and integrated as part of a creative process. Among the visual elements embedded in the multimedia platform are the lines of an old school book to symbolize field notes, a digital sample of wallpaper from the 1930 's, and finally a $15^{\text {th }}$ century medieval illumination. They are all part of the same visual argument, ostensively reinforcing our demonstration. 
Integrating heterogeneous visual or sound element in a film is a well-known process in fiction films. We can refer to Godard's work in several of his films and especially in his Histoires(s) du Cinéma (Jean Luc Godard, 1998). The words, their colours, the font, the rhythm of appearance were an echo of the film's meaning and it was a real interplay between both elements. Godard explained in an interview with Serge Daney (Radio France, 1988) his references to the mute cinema, the caption, the subtitling etc... but with this procedure he created his histories and not the History of cinema. It was a clear appropriation, interpretation, and personal "mise en scène" of the way Godard was telling us his history of cinema.

Claudine de France underlined this aspect in ethnographic film where captions and title played an important role in conveying meaning and interpretation, and were part of the "mise en scène" of the filmmaker. Most of the times in ethnographic film, textual information does not interfere directly with the flow of the activities described: it's before or in between but not during... and for De France this information refers to the indirect commentary produced on an audiovisual production.

11 The relationship between textual information and pictures does not refer to the same categories when integrated in a fiction film or in an ethnographic film. The interpretation of the ethnographer is conventionally accepted in a voice over, or perceived otherwise through the editing structure, or by the captions introduced at the beginning of the film or at the end. The web documentary, the blog and the multi-screen installation question directly these conventions, as does our multimedia writing proposal. These productions offer a new configuration for knowledge restitution. Convinced of the importance of such influential creation, and of the necessity to offer a new space for distribution, we created ${ }^{3}$ three years ago at Le Cube an installation called Digital Anthropologies. The project was to encourage various production formats, where games, cartoons and animations could be among the possibilities employed to convey data collected during fieldwork: edited as testimonies, evocations, analyses and also an invitation for the audience to play and experiment with them.

12 These multilayer and multimodal productions are grounded in our abilities to master and to take over the capacities offered by the programming language. These appropriations give us the possibilities to convey the singularity of the collected data and to offer a personal account of the experiences during our fieldwork. It is an open dialogue between the audience, the filmmaker and the protagonist and an invitation to bridge the gap between our academic institutions and an emerging creative movement of practitioners.

\section{Phanie, a space for creation}

13 In our respective institutions, it would have been rather difficult to find a structure where we could work freely to produce a paper in an interactive format. During 2013, we organized a workshop in the form of a research laboratory again at le Cube, the Digital Art Center, to address these issues and to train interested social researchers by ideating and producing interactive publications within a collaborative dynamic. Caroline Carpentier, webmaster, was one of the people in charge of the training. The objective was to explain the different free access softwares available, and to share their respective capacities such as Joomla, Popcorn, etc. To prolong our collaboration and cooperation, we decided to produce an interactive article based on the open source Parallax, a system 
enriched with HTML 5 and CSS3 - a specific programming language for the integration of animation, text and visuals. looking for when reading a book and watching a film described in a book. The DVD inserted at the end of the publication is sometimes a kind of compromise and an easy way for the publisher to include glimpses of the audio-visual account in the publication itself, without questioning the role of the film in the reading process or questioning the prevalent value of the text on the audiovisual element.

18 audio-visual work - it was like a real flash back of several years. Gilles Remillet and
Nadine Wanono agreed to refer to their previous subject research and to integrate some of the elements collected during this period. For his P.h.D., Gilles focused on the industry and the inner organization of a factory, the workers, the working process and its specific configuration, revisiting well-known images produced by social movements. As for Nadine, she decided to show the organisation of women's daily life in the Dogon country in order to offer a testimony on what we call today the forgotten people, the ones never represented in the pictures.

19 Progressively we decided to share the publication issued from Gilles' P.h.D. as a perfect example of the ways in which films have been most of the time incorporated in our field: at the end of the book, or as an illustration.

20 As Christine watched the movie produced and published on a DVD, simultaneously Nadine read Gilles thesis. We found sequences where pictures were necessary to understand the situation being described, and the textual analysis was crucial to capture the social context, which was not perceivable from the edited sequences. How then could 
we create an article where text and images could be easily accessible on the same level and we could read and watch both elements simultaneously?

Interestingly enough we started by drawing our multimedia paper, by sketching the frames and the content of each of the frames, including the information we focused on and all the data surrounding the content and intrinsically part of it. The way we proceeded, always keeping an eye wide open on the evolution of our project and our goals, gave the four of us a chance to be aware of the challenges we were facing regarding our discipline, Visual Anthropology, in an academic context.

We borrowed from the formal academic structure the way to present our team and our goals: we did it on a notebook, to clearly refer to the old school methodology and the importance of writing on the lines... We look back to our choice ofthe wall paper and the family portraits as a way of introducing a sense of mockery, not towards our respective and common professors but to remind our audience the key role of disrespect in the respective methodology of Jean Rouch and Jean Arlaud. Laughing and inviting the other ones to laugh about themselves: with this surreptitious allusion to the necessary derision towards academia, we introduced not only information regarding our genealogic tree but we recalled the spirit that we have been influenced by, during our training as visual anthropologists ${ }^{5}$ our common sense of derision received as our heritage and maintained as a fundamental dynamic between us.

Fig1 Academic genealogic tree of our team

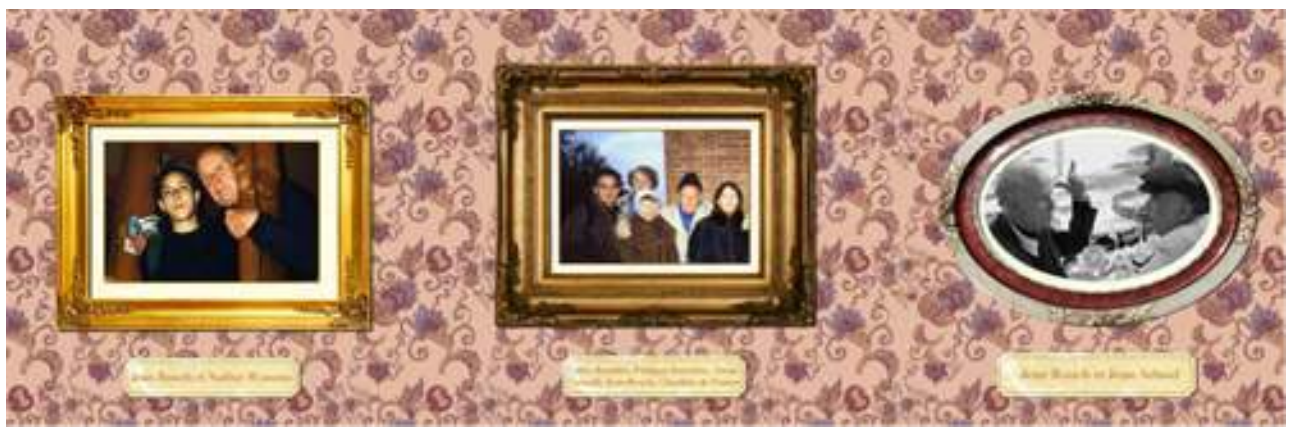

Screenshot from the collective multimedia production

Gilles Remillet 
Fig 2 Academic Genealogic tree of our team

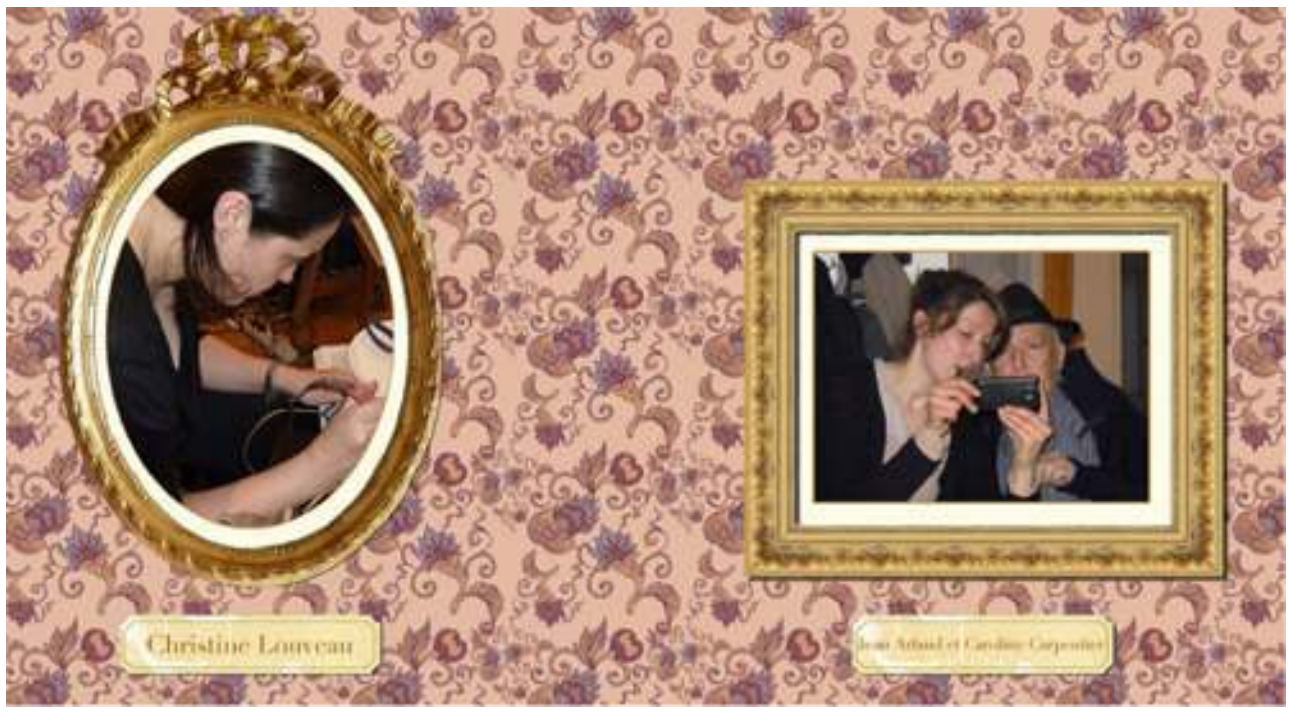

Screenshot from the collective multimedia production

Gilles Remillet

With this brief example based on one frame of the five that we conceived ${ }^{6}$, we could capture the implicit work, which underlines the conception and materialization of this exploratory piece. One layer is still missing, the programming work: the photographic frames scroll on the wallpaper: frames and wallpapers are two distinctive layers. This choice was crucial as the multilayer dimension was not for us a way to have a background behind our ideas or slides, but to use this as two distinctive levels to convey ideas and to play with, in order to introduce a more precise meaning.

If we summarize our choices of visual objects: the field notes, the picture of the brain, the well-known labyrinth of Chartres Cathedral, the tag, and the medieval illumination, we recall "the lineages of collective iconological memory" that Grasseni and Walter referred to in their introduction, quoting Aby Warburg.

This aspect could be perceived as contradictory: trying to convey ideas, analyses of films combining text and pictures on one screen/page and choosing from a range of iconic pictures to recall collective memory. Where does the experimentation, the innovation lie? For us, the purpose was to clearly transmit our message, being sure that the audience would have the same understanding of the implicit background beneath each of these pictures. From this spontaneous interpretation we can introduce a subtler line of questioning.

Do we use field notes and pen as a methodology reduced to merely the size of a piece of paper or do we use an alternative approach to a field already defined by the visualization produced in the mainstream media? By introducing a common picture of the human brain, we questioned the place or the space where multimodal perception could be integrated or visualized. With the labyrinth representation, we suggested the experience of loss of spatial references to ask a question regarding the ways in which we have access to knowledge, and the necessity to wander in unknown spaces in order to invent new strategies.

The way in which we have conceived our analysis revealed the dynamic we were interested in. One layer conveyed the spirit in which we are working and the second one, 
the programming language, gave us the capacities to introduce interactive visualization and to simultaneously present text and filmic sequences. Christine Dole-Louveau de la Guigneraye and Caroline Carpentier concentrated particularly on the Popcorn presentation embedded in the project at http://phanieethnoimage.free.fr/. The four of us decided collaboratively the questions and the goals we would like to obtain and Christine and Caroline took charge of the production of this short excerpt of Gilles' film, which we were actually able to look at while capturing or integrating the missing information that we were looking for while reading the thesis or watching the documentary separately.

Fig 3 Filmic sequence and Textual information with Popcorn

How to read meaningful elements captured by the pictures?

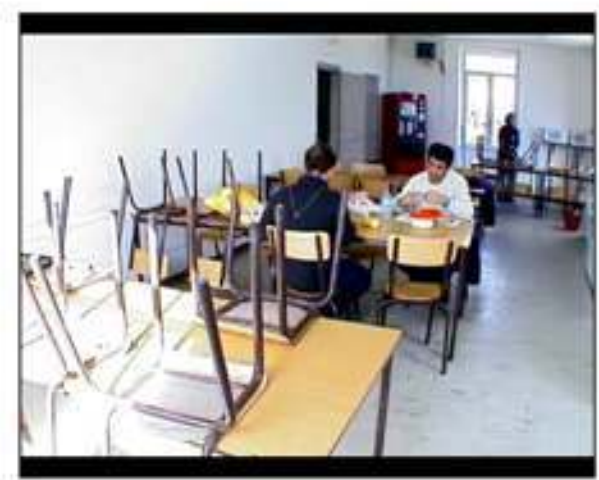

How to understand visual elements from the textual?

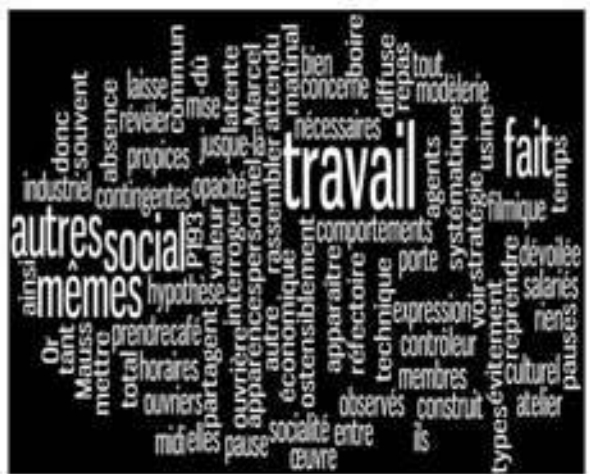

Screenshot from the collective multimedia production

Gilles Remillet

As an experimental proposal it had been conceived with a software in open access. The questions raised during the viewing of the film addressed not only the way we could perceive the filmic situation, but also the way we could apprehend the situation with regard to our social and political awareness. Juxtaposing these questions, almost as a commentary given to the filmic description, is an interpretative dimension missing in the filmic work of Gilles. Within this short and humble proposal we were questioning the possibility to "watch and read" at the same time, namely to capture the background of a filmic work, to render to some extent the information gathered during our fieldwork, whether filming or not, but missing in the final cut especially when the decision was already clearly stated: no commentary along the filmic description.

During the conception and the entire process of programming, which allowed the final result to be shared, we were inspired by a shared understanding of pleasure, enjoyment and collaborative spirit. It was essential to convey this strength of having fun during collaboration and to invite the reader to play around with ideas, manipulations, and programming. It was also a clear invitation to get your hands dirty and to start considering programming as a language with its own rules, power and capacities. 
Fig 4 Proposal of hybridisation of text and image with Popcorn

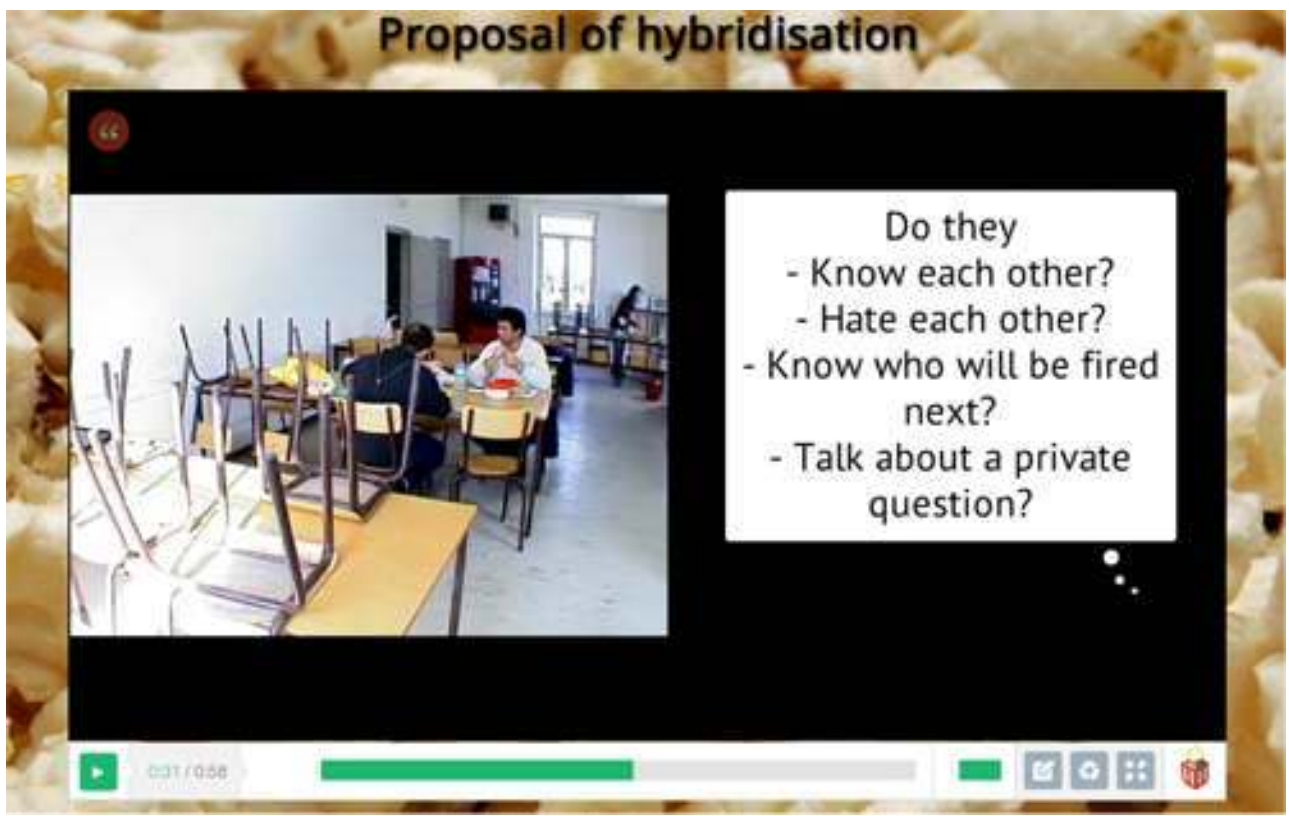

Screenshot from the collective multimedia production

Gilles Remillet

\section{Multimedia writing versus Multimedia creation}

31 Our multimedia article was an invitation to examine, from a very concrete example of a collaborative, multi-linear approach, the ethnographer's position, the methodology employed and the goals of such hybrid composition. One of the goals was to create the conditions to examine precisely the role and place of the programming language in the knowledge production process. Even if several of us were convinced and have been engaged for many years on this specific topic, unfortunately, too few people coming from the field of Visual Anthropology take into consideration these reflections.

Fig 5 Frame of one of our interactive questions

\section{Methodology}

The problematic of our presentation is to render the questions and difficulties when your mind is split in two, following the resources you are working on from the same film we try to underline:

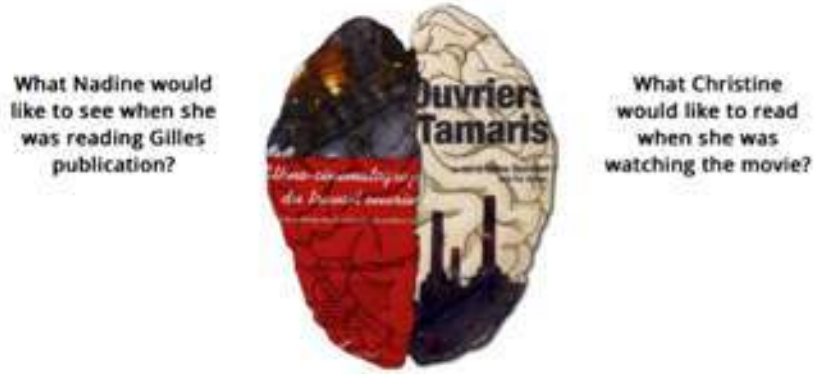

How did Gllles react to our comments, critics, frustrations?

Screenshot from the collective multimedia production

Gilles Remillet 


$$
\text { first one is the collaboration between different competencies: web designer, programmer, }
$$
anthropologists, and visual anthropologists.

"Today everyone with an iPhone knows that it would be absurd to distinguish what has been designed from what has been planned, calculated, arrayed, arranged, packed, packaged, defined, projected, tinkered, written down in code, disposed of and so on. From now on, "to design" could mean equally any or all of those verbs. ....In other words, You in design as well as We in science and technology studies may insist that objects are always assemblies, "gatherings" in Heidegger's meaning of the word, or things and Dinge, and yet, four hundred years after the invention of perspective drawing, three hundred years after projective geometry, fifty years after the development of CAD computer screens, we are still utterly unable to draw together, to simulate, to materialize, to approximate, to fully model to scale, what a thing in all of its complexity, is." From $A$ Cautious Prometheus? A Few Steps Towards the Philosophy of Design (With Special Attention to Peter Sloterdijk. Keynote lecture for the Networks of Design). 2008

Producing an exploratory research multimedia article was an obvious response to tackle this difficulty and to ask readers to evaluate by themselves the interest of such cooperation. It was a real challenge to present a process, a "thing", a dynamic. The second challenge clearly identified by Latour also, is the question of the creation, the circulation of objects, as reasoning tools:

"What is needed instead are tools that capture what have always been the hidden practices of modernist innovations: objects have always been projects; matters of fact have always been matters of concern. The tools we need to grasp these hidden practices will teach us just as much as the old aesthetics of matters of fact and then again much more. Let me be clear I am not advocating another CAD design for Prometheus. What I am pressing for is a means for drawing things together gods, non- humans, and mortals included. Why should this prove to be an impossible task? Why can the powerful visual vocabulary that has been devised in the past by generations of artists, engineers, designers, philosophers, artisans and activists for matters of fact, not be devised (I hesitate to say restyled) for matters of concern?" From A Cautious Prometheus? A Few Steps Towards the Philosophy of Design (With Special Attention to Peter Sloterdijk). Keynote lecture for the Networks of Design. 2008

of course our very humble collaborative project does not pretend to produce such a tool but it was an attempt to connect "Praxis when Action is Interaction" to "Poiesis for Interpretation and Narration", making sense and referring to an aesthetic that we could characterize as "apodictic aesthetic", namely an aesthetic that demonstrates as much as it visualizes.

Obviously, the code and the programming language provokes and questions epistemological grounded beliefs that are rooted in our methodologies and respective disciplines, but also offers a new space and new possibilities to render complex realities that we faced during our field work.

Since 2004, Nadine focused on code as a possible language for representing the complex realities she faced during her fieldwork as a visual anthropologist. She left the "cinema as machine of the visible as Comolli once phrased it" (Parikka 2012-35), to integrate code as a possible language to reveal invisible manifestations or relations. 

worked on different possibilities of modeling and simulation, which now offers her access to "apodictic aesthetic" as defined above. This research on code, its utilisation and the multiple modeling that Nadine could work on, gave her access to these new forms of representation and helped her modify her approach in order to propose an innovative relationship between "documented realities and their audio-visual interpretation" (Wanono 2012-4). As anthropologists and filmmakers, digital programming provide us the opportunity to create ways of representing the invisible through software, "visibly invisible or invisibly visible essence » (Chun 2010-35). When Chun (2008-70) identifies the " code as re-source ", positioning an « interface as a process rather than as a stable thing ", it resonates with Simondon and the concept of individuation. In Mode of existence of technical object, the author explained:

"...the machine is an alien; it is an alien that has something of the human is locked in, unrecognized, materialized, enslaved, but human nonetheless. The most powerful cause of alienation in the contemporary world resides in this failure to understand the machine, which is not caused by the machine but by the non-understanding of its nature and its essence, by its absence from the world of meanings, and by its omission from the table of values and concepts that are part of culture."..."The real improvement of machines, that which can be said to raise the level of technicity, has nothing to do with an increase in automatism but, on the contrary, with the fact that the functioning of a machine conceals a certain margin of indeterminacy. It is this margin that allows a machine to be sensitive to outside information".

The programming language is as invisible as it is crucial in all the process of writing and conceiving of a multimedia production. We all have been trained to express and publish our research by demonstrating our point of view in accordance with the surrounding scientific background and with appropriate examples from our respective fields. The conceptual abstraction, at the core of the demonstration process, the distance from our subject, is necessary in order to convey a reasoning recognized as such by the scientific sphere. Each step is cautiously taken to convince the reader to pursue the progression and the deployment of concepts along the logical path.

As soon as we adopt the rules prescribed by production and multimedia we are wandering in a space, which introduces us to conditions of experience. Deleuze explained:

“...the condition must be a condition of real experience, not of possible experience. It forms an intrinsic genesis, not an extreme conditioning. In every respect, true is a matter of production, not of adequation". Difference and Repetition (Gilles Deleuze 1968-154)

In short, Deleuze's response to Kant and Hegel is not a return to classical empiricism or the primacy of the actual in sense-experience. He argues that experience itself is the result of a genesis that is both creative and open, and which contains its own necessity." http://larvalsubjects.wordpress.com/2007/09/11/sensation-and-sensibility-deleuzesaesthetic-metaphysics/

41 By following this invitation we are clearly challenging the conditions of scientific knowledge production. Is the ethnographer becoming an artist and programmer in order to produce a multimedia creation? We refer to the article of Christa Sommerer and Laurent Mignonneau entitled "From the Poesy of programming to Research as an Art Form": "One of our main motivations for writing our own software programs and developing our own hardware interfaces as opposed to using off-the-shelf software packages or 
commercially available interface technology is our wish to develop systems that investigate new questions and explore novel technical, conceptual and artistic approaches. As media artists we have chosen to become artists/researchers or researcher/artists who define and shape new questions of creation, and set out to explore the forefront of creativity and digital technology, investigating the basic question of creation, invention and discovery" Code the Language of Our Time (Christa Sommerer and Laurent Mignonneau, 2003-1).

By examining the conditions, values and interest of these multi-linear, multi-sensory and multi-voice formats, we should be more precise regarding the position of the ethnographer versus the programmer. Is it necessary to be a programmer or an artist for the ethnographer to produce a non-linear argument? Should we organize educational programs on programming as we did with the camera and the microphone? And, should we introduce specific training on the role and value embedded in the tools that we use in Visual Anthropology. This reflection was part of Nadine's and our team's agenda and it is why she introduced the necessity to take into consideration the consequences and influences played by the camera on knowledge production.

As an example, we can go back to the appearance of the concept of "Shared Anthropology" introduced by Rouch, after his first experience of feedback in Niger with the Sorko fishermen giving him advice on the role and value of the soundtrack during a hippopotamus hunting. It was because Rouch could screen his film in Niger in the small village of Ayorou that he could benefit from the cultural understanding of the hunting process. This exchange between the people and the filmmaker opens the field of Shared Anthropology as a methodology we should all employ. The technical apparatus engaged in such revelation has not really been taken into account, even if the people underlined the misunderstanding of the hunting process and also revealed their relation to the film as a magnifier of the real: the hunt should be silent! We kept the methodology as a pure conceptual phenomenon outside any cultural, political, and technical surrounding.

\section{Our collaboration around the programming language}

We all agreed to think in accordance with a "parallax dynamic". We decided to abandon the frame and the page as implicit rhythm with which to unfold our reasoning. The transition was very fluid and we could pass from one idea to the other without a clear split from one to the next. The parallax structure, articulated on two layers, gave us the freedom to go back and forth between two visualizations and to repeat it without introducing in the spirit of the viewer, a feeling of going backwards. From another point of view, we should mention that this fluidity should be carefully controlled by the speaker who is still evaluated for his/her capacities of demonstration during a formal talk, and that the transition should be carefully accentuated by the speaker, otherwise the audience could hardly follow the progression of the arguments. This environment, in fact, is meant for a performance, not for self-browsing.

Parallax is a scrolling technique used by computer graphics in which background images move more slowly than images in the foreground, creating the illusion of depth and immersion. For example, one approach involves the creation of image layers through attribution, followed by assigning a scroll function and designating speeds for each item. 

collaborative effort in which programmers constantly improve the code and share the changes within the community, and is usually available at no charge under a license defined by the Open Source Initiative. Then we continued on the integration of the HTML 5 and CSS3 for the animation aspects. Several times Caroline showed us the code underlying each animation or visualization in order to invite us to see the two ways of writing, or reading the same message. HTML5 is a mark-up language for structuring and presenting content for the World Wide Web and is a core technology of the Internet. It includes detailed processing models to encourage more interoperable implementations. For the same reasons, HTML5 is also interesting for cross-platform mobile applications. Many features of HTML5 have been built with the consideration of being able to run on low-powered devices such as smartphones and tablets. mapper because we are not anymore working on a single country scale but we collaborate on an international level, completing the code, transforming it, enriching it from one country to another without borders. But we have to really be cautious, as we are quite aware of the political control over the Internet and governmental censure, which controls exchanges between countries. Even if the open source gives us the capacity to collaborate without frontiers, we cannot perceive Internet as a space of freedom disregarding any economic control or any political power.

The lack of training in this domain, closely linked to our symptomatic incapacity to take into account technical apparatus - as if they did not have any interaction with our intellectual sphere - work in favour of the invisibility of these exchanges. More importantly, we don't perceive this phase of programming language as part of our knowledge production. Instead, the multi-linear creation implies a collaborative approach with a programmer who could also have training in anthropology.

Fig 6 The code-writing process underneath

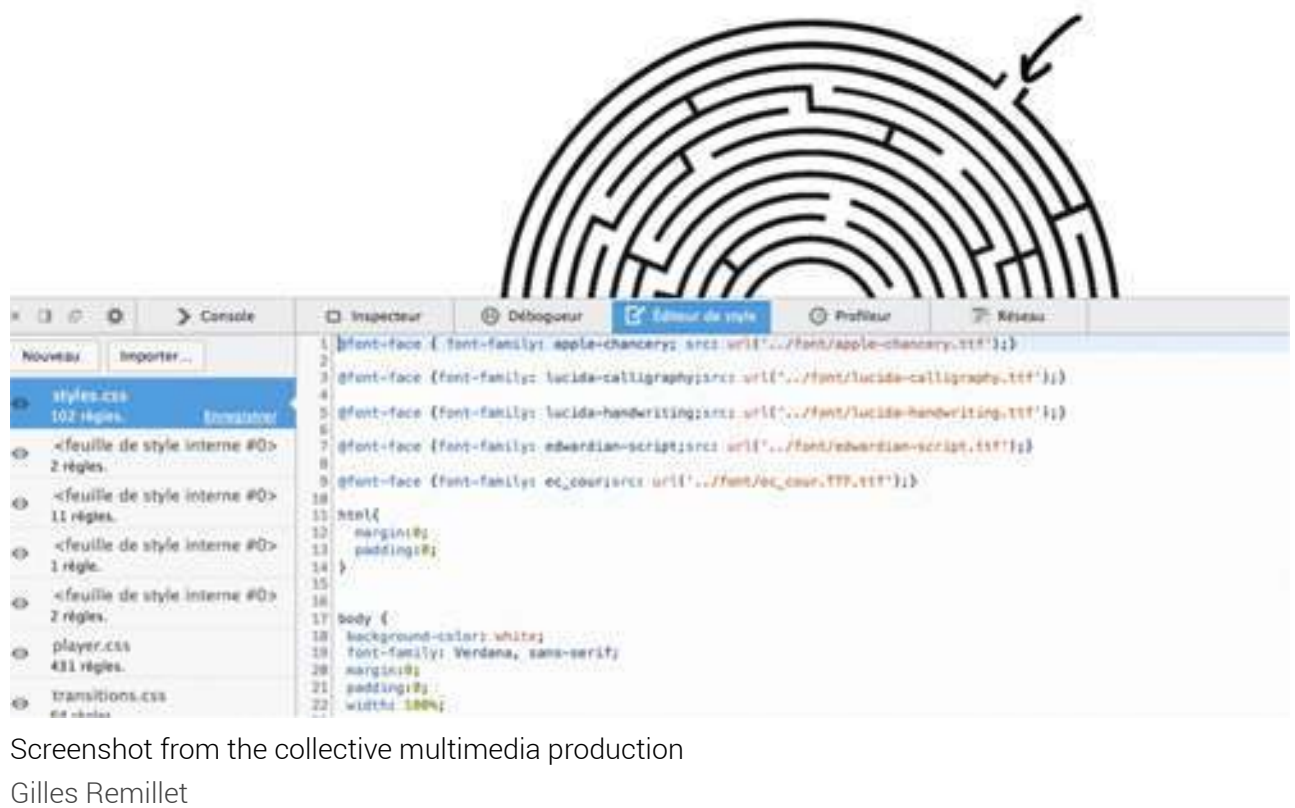

Anthrovision, 2.2 | 2014 

transitioned from the analogue editing table to the video editing suite to the Final Cut Pro software, editing as a process of assembling ideas, arguments, and narrative remains the same. Obviously with the video and the digital FCP suite, the technical limitations have become fewer and fewer, and we could edit a film from start to end without any difficulty. We could have as many versions we need without any loss of definition etc. The programming language could be perceived as much more complex. As an example, Parallax comes from the video game industry, not only in a domain quite far from the academic, but referring to a culture, a practice, an aesthetic mainly familiar to the younger generation. levels of visibility. When teaching the structure of a film one can explain the cut, the frame, the speed and all the aspects of the editing language, but if we would like to reveal the programming we should look at the bottom line or beneath the pictures in order to discover the language employed to render the effects.

53

Could we compare this collaboration to the ones we could have with an editor? This questioning editing/ rushes as if we were at the same stage of finishing a shooting and we should edit without the constraints of the linear narrative of the film.

We could propose this writing process and conception process as two sides of the same message and then as a translation: one with language code and the other one with pictures, sounds, effects and dynamic. Both are closely linked and we should be able to know as well as possible the programming language in order to conceive and produce a singular and pertinent contribution.

Fig 7 The illumination and its code to separate the textual and the visual elements

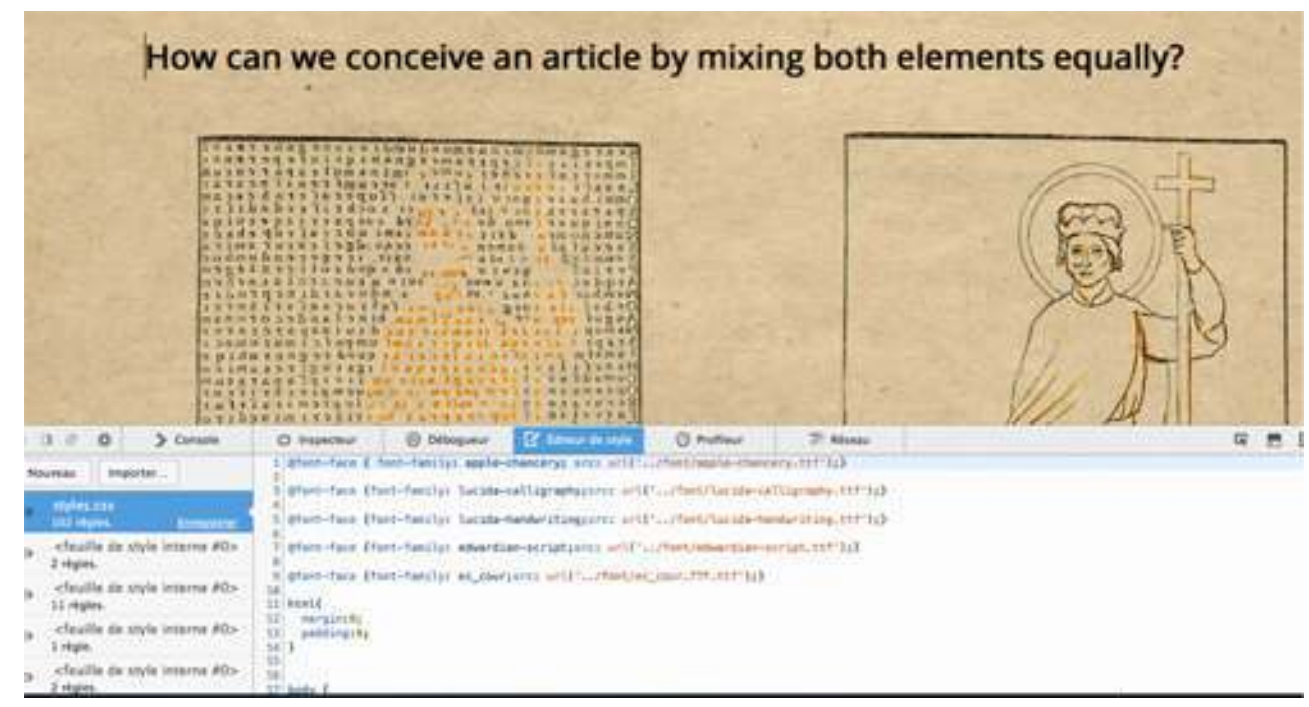

Screenshot from the collective multimedia production

Gilles Remillet 
Fig 8 The illumination in its initial stage

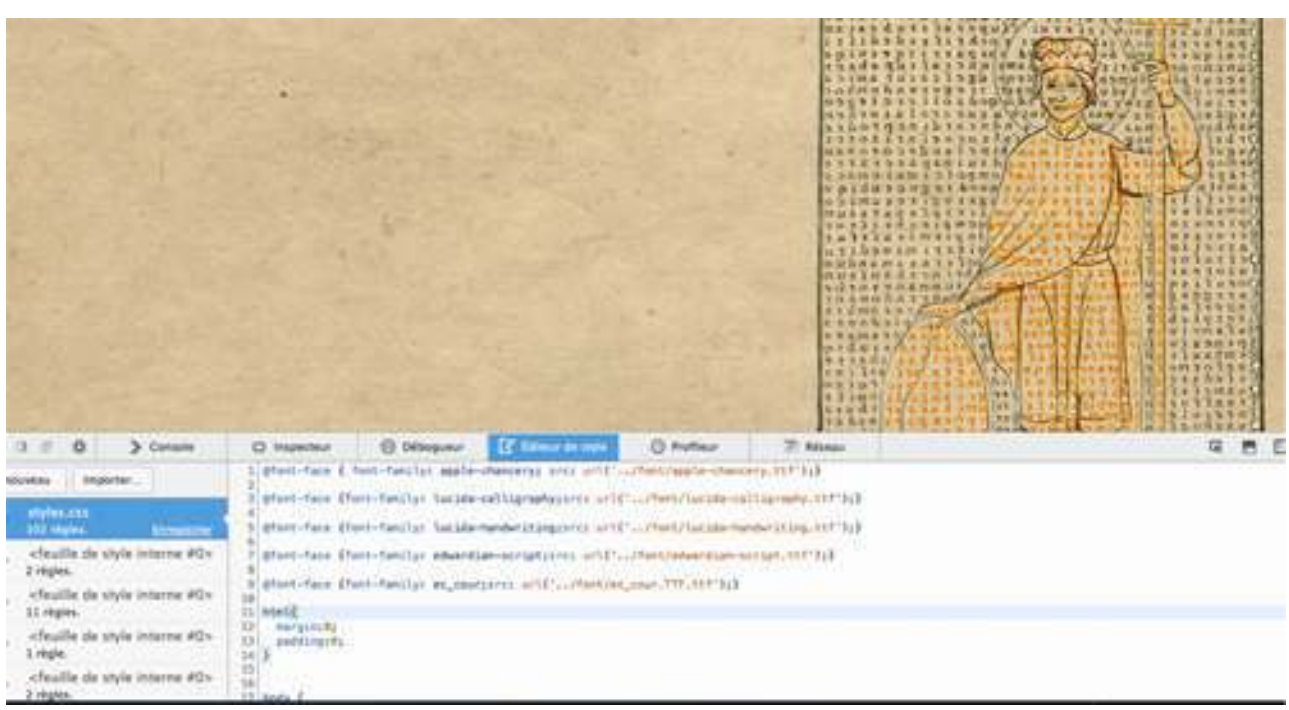

Screenshot from the collective multimedia production

Gilles Remillet

As the Commission of Visual Anthropology is actually trying to define academic criteria in order to evaluate articles produced with both text and images as a publication, this process forces us to be faced with important questions regarding our discipline.

By producing a multimedia, which category do we belong to as ethnographers? Are we author, co-author, scientific advisor, or programmer? Is the production itself conceived and perceived as a creation, a vulgarization or a scientific production? What could be the consequences for our discipline and the mode of evaluation?

The modest example we produced gave us the possibility to share questioning on the nature of the multimedia, its classification, and links to the creative activity. It also allowed us to really consider the crucial necessity to integrate in our training the technical apparatus as an active component in our knowledge production and the necessity of creating programming language in accordance with the specificities of our field data.

\section{BIBLIOGRAPHY}

Bryant, Levi R. 2008. Difference and Givenness: Deleuze's Transcendental Empiricism and the Ontology of Immanence Northwestern University Press.

Chun, Wendy. 2011. Programmed Visions: Software and Memory MIT Press.

-2008 The Enduring Ephemeral, or the Future is a Memory. Critical Inquiry 35: 1 148-171.

Reprinted in Place Studies in Art, Media, Science and Technology: Historical Investigations on the Sites and the Migration of Knowledge. Eds. Andreas Broeckmann and Gunalan Nadarajan (Berlin: Verlag und Datenbank fur Geisteswissenschaften, 2009. 
France, Claudine de. 1995 « Le commentaire rival de l'image dans la mise en scène du réel », Xoana. Images et sciences sociales, $n^{\circ} 3, \mathrm{pp} .73-88$.

-1994 « Réflexion sur le commentaire de film », Cinéma, rites et mythes contemporains, (10),

E.P.H.E Sciences religieuses, , pp. 11-19.

-1985 « Image et commentaire : du montré à l'évoqué », Hors Cadre, n³, pp. 133-153.

Latour Bruno: http://www.bruno-latour.fr/sites/default/files/112-DESIGN-CORNWALL-GB.pdf (p.2).

http://www.bruno-latour.fr/sites/default/files/112-DESIGN-CORNWALL-GB.pdf (p.10).

Novak, Marcos. 2002. "Speciation, Transvergence, Allogenesis: Notes on the Production of the Alien”, Architectural Design vol. 72 n³.

Parikka, Jussi. 2012. What is Media Archaeology? Cambridge Polity Press.

Remillet, Gilles. 2009. Ethno-cinématographie du travail ouvrier. Essai d'anthropologie visuelle en milieu industriel, Paris, L'Harmattan, coll. "Champs visuels", 349 p.

Links to the film:

http://www.editions-harmattan.fr/index.asp?navig=catalogue\&obj=video\&no=2038

Somerrer, Cristina. and Mignonneau, Laurent. 2003. Code the language of our time, in Ars Electronica Archive.

Simondon, Gilbert.1958. Mode of existence of technical object, Paris Aubier, Editions Montaigne. http://fr.scribd.com/doc/139180528/Gilbert-Simondon-On-the-Mode-of-Existence-of-TechnicalObjects-translation-thus-far-2010 (p.3)

Wanono, Nadine. 2012. Creation et Transmission en anthropologie visuelle, Co-eds Accolas Sophie, Journal des Anthropologues, n 130-131.

- 2012 « La caméra et les techniques du croire » Publié in L'objet milieu, Revue Le Philotope, $\mathrm{n}^{\circ} 9$.

- 2014. From the Grain to the Pixel, In Experimental Film and Anthropology, Arnd Schneider and Caterina Pasqualino (dir), Bloomsbury Academic, pp.183-198. (forthcoming)

- 2004 « From Spatial Analysis to Virtual Wonder », in P.I. Crawford and M. Postma (dir.), Visual Ethnography and Anthropological theory, Intervention Press, Aarhus.

- 2008 « La singulière collection de Jean Rouch », in Lise Boily and Francis Rousseaux (dir) La collection, un lieu privilégié pour penser ensemble singularité et synthèse. Recherches sémiotiques /Semiotic Inquiry. Association canadienne de sémiotique / Canadian Semiotic Association

Interview:

Godard, Jean Luc. 1988: http://www.ina.fr/audio/PHD98044206

\section{NOTES}

1. in the issue $6 / 7$

2. Caroline Carpentier, Webdesigner, coordinatoor at Phanie, Ph.D. student at Evry IUT, Christine Dole-Louveau de la Guigneraye, Maître de conférences in communication at Evry IUT, President of Phanie, Gilles Remillet, Maître de Conférences, University Paris Ouest Nanterre La Défense 
H.A.R, Nadine Wanono, Researcher, CNRS-IMAf-EPHE-EHESS-AMU-IRD. The project is http:// phanieethnoimage.free.fr/

3. The public event is part of the activities organised by Les Ecrans de la Liberté, an association created by Pascal Leclercq, Jacques Lombard and Nadine Wanono.

4. Jean Arlaud, Emeritus Professor in Ethnology and Cinema at Paris 7 university (1938-2013).

5. If we go back to the moment of our presentation during the IUEAS panel, one person immediately expressed his appreciation regarding the combination between the frames, the wallpaper and the genealogic tree, commending our work as the one done by the French team.

6. To see these frames in the live context of our research action proposal go to: http:// phanieethnoimage.free.fr/

\section{ABSTRACTS}

Deeply affected by new forms of interactive, multimodal and multilayer productions of data, we developed a research project around this question. Our team put in place an audio-visual and textual collaboration project to be presented during the $17^{\text {th }}$ IUAES World Congress in Manchester, addressing the issue of establishing academic standards of evaluation for nonliterary forms of representation in Anthropology. By describing and analysing the modalities of this experimental production (http://phanieethnoimage.free.fr/), we will underline the key moments revealing the challenges, the interests and the questions that we would like to share, in order to encourage this experimental approach and this dynamic of creation as part of a possible methodology.

Particulièrement intéressés par les nouvelles formes d'écritures interactives et collaboratives, nous voulions initier un projet de recherche autour de cette question. Notre équipe décida de produire collectivement un article conçu à partir d'éléments visuels et sonores afin de le présenter dans le cadre du $17^{\text {ème }}$ congrès mondial de IUAES qui cherchait à établir des critères académiques d'évaluation pour les productions multimédia en anthropologie. En décrivant et en analysant les modalités de réalisation de notre production expérimentale, nous soulignerons les moments clés qui rendent compte des enjeux, de l'intérêt et des questions que nous voulons partager afin d'encourager ces approches expérimentales et cette dynamique de création comme une méthode à part entière.

Particularmente interesados por las nuevas formas de escrituras interactivas y colaborativas, queríamos iniciar un proyecto de investigación en torno a este tema. Nuestro equipo decidió producir de forma colectiva un artículo concebido a partir de elementos visuales y sonoros para presentarlo en el marco del decimoséptimo congreso mundial de IUAES que pretendía establecer criterios académicos de valoración para las producciones de los medios de comunicación en antropología. Describiendo y analizando las modalidades de realización de nuestra producción experimental, haremos hincapié en los momentos claves que dan cuenta de los retos, del interés y de las preguntas que queremos compartir para fomentar y considerar estos enfoques experimentales y esta dinámica de creación como un método en sí. 
INDEX

Keywords: Interactive, multimodal publication, collaborative project, audio-visual textual project, programming language, code, visual anthropology

Palabras claves: Interactiva, publicación multimodal, proyecto en colaboración, proyecto textual y audiovisual, lenguaje de programación, código, antropología visual

Mots-clés: multimodale publication, projet collaboratif, project audio-visuel et textuel, langage de programmation, anthropologie visuelle

\section{AUTHORS}

\section{GILLES REMILLET}

Maître de Conférences, University Paris Ouest Nanterre La Défense H.A.R

\section{NADINE WANONO}

Tenured Researcher, CNRS-IMAf-EPHE-EHESS-AMU-IRD 